\title{
LACK OF ANTIBODIES TO CORONAVIRUSES IN A CAPTIVE CHEETAH (ACINONYX FUBATUS) POPULATION
}

\author{
JENNIFER A SPENCER*
}

\section{ABSTRACT}

Cheetahs (Acinonyx jubatus) $(n=40)$ were tested by means of an immunofluorescent test (IFT) for the presence of antibodies to the feline coronavirus group. All cheetahs tested negatively and this was further confirmed by virus serum neutralisation.

Key words: Cheetah, Acinonyx jubatus, coronavirus, immunofluorescent test.

Spencer J.A. Lack of antibodies to coronaviruses in a captive cheetah (Acinonyx jubatus) population. Fournal of the South African Veterinary Association (1991) 62 No. 3, 124-125 En.) Department of Infectious Diseases, Faculty of Veterinary Science, University of Pretoria, Private Bag X04, 0110 Onderstepoort, Republic of South Africa

Feline infectious peritonitis (FIP) is a sporadic, highly lethal coronaviral disease of Felidaelo. Recent sero-epidemiological surveys have demonstrated that infection with feline coronaviruses is prevalent in 20 to $30 \%$ of domestic cats in the general population worldwide, and in multi-cat households, this rate may even be as high as $100 \%{ }^{10}$. The disease has been recognised in Europe, North America, Australia, Japan and South Africa. The natural host range of FIP virus (FIPV) includes domestic and non-domestic felids such as cheetah (Acinonyx jubatus), lion (Panthera leo), serval (Felis serval), caracal (Felis caracal) and leopard (Panthera pardus) ${ }^{123}$ 89.

The relatively low numbers of cheetah in the wild 5 has led to the establishment of various captive breeding programmes where the animals may come into contact with feral cats. This, as well as the fact that cheetahs have been proposed to lack genetic variability, make them highly susceptible to infectious diseases ${ }^{6}$. Subclinical coronavirus infection ${ }^{4}$ as well as epidemics of FIP ${ }^{3} 8$ have been reported

\footnotetext{
$\star$ Department of Infectious Diseases, Faculty of Veterinary Science, University of Pretoria, Private Bag X04, 0110 Onderstepoort, Republic of South Africa
}

Received: January 1991 Accepted: April 1991 in captive cheetah populations. It is important to monitor the immune status of the cheetah, as well as to be in a position to certify a group of cheetahs free of coronaviral infection, as this may have important management implications. For this purpose, a rapid serological test was developed for the detection of antibodies to the coronaviruses in cheetahs kept at the De Wildt Cheetah Breeding Centre of the National Zoological Gardens of South Africa at De Wildt.

Forty cheetahs which were housed in small groups in wire enclosures were investigated. They were separated from other species at the Centre by these fences, but the camps were accessible to feral cats. The age range of the cheetahs varied from a few months to 14 years. There has not been any evidence of clinical FIP in this group to date.

Two samples of $10 \mathrm{ml}$ of blood were drawn into plain tubes from the medial saphenous vein, one month apart, from each cheetah during 1989 (total of 80 samples). The blood samples were then centrifuged and the serum drawn off and frozen until tested.

An indirect IFT, using foetal cat whole foetus (FCWF) cells (obtained from $\mathrm{Dr}$ Pedersen, UC, Davis, in 1984), infected with a field isolate of FIP virus (strain CAC 230 obtained from Wellcome Research Laboratories, Kent, England), fixed onto multi-well test slides, was used to detect the presence of antibodies in the serum samples of the cheetahs. Monolayers of virus-infected cells were harvested by trypsinisation when about $40 \%$ of the cells showed cytopathic changes. The cells were washed 3 times with phosphate-buffered saline (PBS), mixed with equal amounts of uninfected cells and air dried onto the slides $\left(3 \times 10^{3}\right.$ cells per well). The slides were fixed in chilled acetone for $10 \mathrm{~min}$, dried and stored at $-20^{\circ} \mathrm{C}$ until used. The cells were covered with $20 \mu 1$ volumes of a 1:10 dilution of either test serum or positive control. The positive control consisted of peritoneal fluid and serum obtained from a clinical case, and having a fluorescent response of $3+$ at 1:400 dilution. The slides were incubated for one hour at $37^{\circ} \mathrm{C}$ in a humid chamber and subsequently washed 3 times in PBS and once in distilled water. After air-drying, $20 \mu \mathrm{l}$ volumes of a 1:50 dilution of fluorescein isothiocyanate (FITC) labelled rabbit anti-cat IgG (Zymed laboratories, San Francisco, CA) were applied to the cells. The slides were incubated, washed and dried as before and mounted in buffered glycerol $(\mathrm{pH} \mathrm{7,8)}$. The cells were examined for specific reactivity using a fluorescence microscope.

FCWF cells $(0,2 \mathrm{ml})$ were seeded in 96 well microtitre plates. When the cells were confluent, the medium was removed and replaced with $0,1 \mathrm{ml}$ fresh medium, $50 \mu 1$ of virus and $50 \mu 1$ of a 1:5 dilution of test serum or positive control. The virus was seeded in 6 dilutions: $10^{-2}$ to $10^{-7}$. The plates were examined daily for cytopathic effect (CPE).

None of the 80 samples tested showed specific reactivity when examined with the fluorescence microscope. The positive control, on the other hand, showed strong fluorescence when examined at the same dilution. This absence of specific fluorescence, indicated a lack of antibodies to the feline coronaviruses, in cluding FIP, in this cheetah group. This was further confirmed by virus neutralisation, as, by Day 1 there was a $4+\mathrm{CPE}$ in all the samples, showing a lack of antibodies in the sera.

Reports of FIP disease in cheetahs have been scarce and clinical outbreaks have rarely been reported. Colly ${ }^{2}$ reported a loss of 2 adult cheetahs on their intro- 
duction to the Johannesburg zoo. Evermann et al., ${ }^{3}$ and $P$ feifer ${ }^{8}$ reported on an outbreak in Oregon in which serious losses occurred. However, the presence of coronavirus antibodies with no clinical FIP disease, was reported in a group of wild-caught cheetahs by Horzinek \& Osterhaus ${ }^{4}$.

No antibodies to coronaviruses could be detected in the study group. These animals therefore constitute a FIP-free population. This has important implications; firstly they serve as a population from which animals can safely be introduced into established breeding groups and, secondly, they constitute a highly susceptible population which emphasises the need for screening of all newcomers to the group.

Feline infectious peritonitis is an immune mediated disease ${ }^{7}$. It is therefore largely dependent on the state of the cell mediated immunity (CMI) of the animal.

\section{ACKNOWLEDGEMENTS}

The author wishes to thank Prof J A W Coetzer, Miss $\mathrm{H}$ Snyman and Mrs R Roos. The co-operation of the staff of the National Zoological Gardens and De Wildt Cheetah Research Centre is also gratefully acknowledged.

\section{REFERENCES}

1. Appel M 1987 Virus infections of carnivores. Elsevier Science Publishers, Amsterdam: $419-420$

2. Colly L 1973 Feline infectious peritonitis. Veterinary Clinics of North America 3: 34

3. Evermann J, Burns $G$, Roelke $M$, McKeirnan A, Greenlee A, Ward A, Pfeifer M 1983 Diagnostic features of an epizootoc of feline infectious peritonitis in captive cheetahs. American Association of Veterinary Laboratory
Diagnosticians, Annual Proceedings: 365-382

4. Horzinek $M$, Osterhaus A 1978 Feline infectious peritonitis: a worldwide serosurvey. American Journal of Veterinary Research 40: 1487-1392

5. Morsbach D 1987 Cheetah in Namibia. Cat News 6: 25-26

6. O'Brien S, Wildt D, Goldman D, Merril C, Bush M 1983 The cheetah is depauperate in genetic variation. Science 221: 459-462

7. Pedersen N 1983 Feline infectious peritonitis and feline enteric coronavirus infections. Feline Practice 13: 5.20

8. Pfeifer $M$, Evermann J, Roelke $M$, Gallina A, Ott R, McKeiman A 1983 Feline infectious peritonitis in a captive cheetah. Journal of the American Veterinary Medical Association 183: 1317.1319

9. Van Rensburg I, Silkstone M 1984 Concomitant feline infectious peritonitis and toxoplasmosis in a cheetah (Acinonyx jubatus). Journal of the South African Veterinary Association 55: 206-207

10. Weiss R 1978 Feline infectious peritonitis - an update. Modern Veterinary Practice 59: 832-836 